\title{
MODULARIZATION OF ENGINEERING CONTENT ADAPTED TO SOCIAL NETWORK
}

\author{
L.I. Hojas Hojas', E.M. García Del Toro', I. Hojas García-Plaza² \\ ${ }^{1}$ Universidad Politécnica de Madrid, ETS Ingeniería Civil (SPAIN) \\ ${ }^{2}$ Georg-August-Universität, Göttingen (GERMANY)
}

\begin{abstract}
The COVID19 pandemic has caused a deep social and economic crisis but it has also stimulated the use of tools, which, being already operational at the social level, can be integrated into the training processes immediately.
\end{abstract}

The main problem that we have found in the use of messaging tools, such as WhatsApp or Instagram to give two examples, is the structuring of the teaching objectives and the organization of the training processes.

The training that we are currently teaching is aimed at blocks of activities lasting approximately one hour and with a curricular organization divided into blocks usually between 3 and 6 ECTS credits (European Credit Transfer System).

ECTS credits are the acronym for the European Credit Transfer System and it is the model adopted by many universities in the European Higher Education Area (EHEA) to try to homogenize higher education.

A bachelor's degree has 240 credits, divided between 40 and 50 subjects, with an activity per subject of between 75 and 180 hours.

This model is very rigid and is poorly adapted to the content division promoted by training systems based on messaging applications.

In some countries, such as Spain, there is strong administrative control in the teaching programs that are approved.

In the society of the XXI century, the rigidity of the training system and the organization of the contents in blocks called subjects, with a teaching load of the order of 90 hours per subject, are a problem for learning in the areas called STEM (science, technologies, engineering and matemathics).

This text presents an engineering training proposal divided into more operational units for teaching on mobile platforms and much more flexible in order to adapt to the labor market both in the present and in the philosophy of continuous training throughout the lifetime.

Keywords: Modularize, ECTS, OKR, STEM, Rodrik trilemma, Lifelong Learning, Open education and Networked learning.

\section{INTRODUCTION}

The pandemic produced by COVID19 has caused a profound social and economic crisis, but it has also stimulated the massive use of online tools and social networks, in training processes.

The accessibility of the subjects is determined by the intensive use of certain computer tools and in particular of social networks.

The European Parliament and Commission are studying the future of education in Europe in the context of COVID-19[1]. However, up to now the debate seems more oriented to find to a common regulation and frame of reference than to promote of open, competitive tools to stimulate the training processes.

The use of internet-based communication networks began in the 90s, and and has until now, only increased, with its maximum peak found today. Its use has become widespread, driven by the daily use of social networks, which has favored the relationship of members of the educational community.

The training contents are currently divided into two large groups: regulated training and non-regulated training. The first group or formal or official training is aimed at obtaining official degrees. It is 
organized into large training blocks, which we call subjects, with an average teaching load of between 3 and 6 ECTS credits (European Credit Transfer System). The group of non-regulated training would be made up of all kinds of more informal training oriented to gain knowledge in accordance with the needs of society.

ECTS credits are a tool to adapt the educational effort in the different centers of the European Higher Education Area (EHEA) and we will use them as a reference for the analysis of the activities in this document.

A bachelor's degree usually has an average of 240 credits (Spain), divided between 50 and 60 subjects, with an activity of between 3 and 6 ECTS credits Which means between 80 and 180 hours of work for the student. For the integration of training throughout academic life, we consider it to be too high a training unit. Figure 1 shows the classic organization of a university degree in Spain.

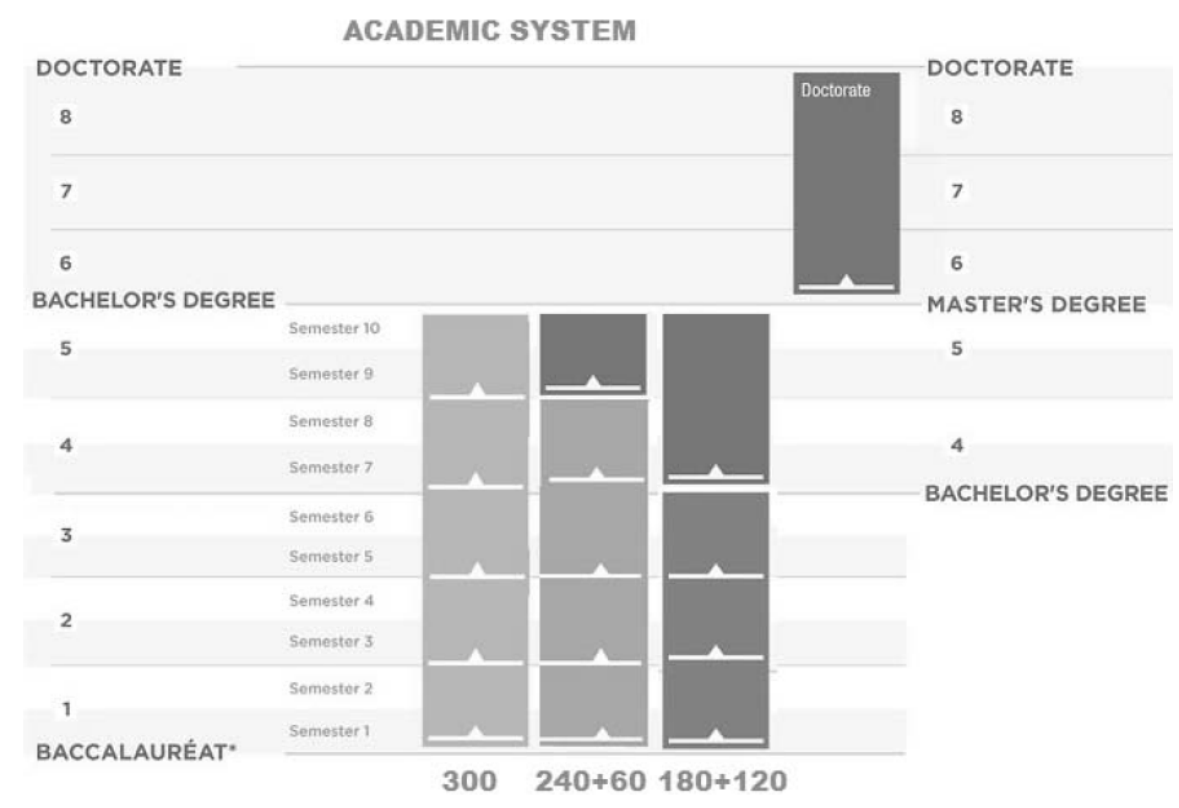

Figure 1: Classical organization model of credits in a university degree in Spain

Educational models are different in different countries. In some of them, such as Spain, there is a strong administrative control in the teaching programs and it is the administration, together with some approval and quality agencies that authorize the training proposals.

This form of regulation of the different training cycles is not efficient, since the changes require a lot of bureaucracy and a long time until they become effective. To this must be added the ineffectiveness of the methods used both in continuous training for professionals who wish to retrain, and in training to adapt the unemployed to the current demands of the labor market. Teaching must integrate both preparation for work and ongoing training and to achieve this, existing training models must be changed.

In Spain it is common for graduates to take some additional preparation courses aimed at the labor market at the end of their studies. But it is the companies themselves that adapt the graduates they hire to the work methodologies that they are going to carry out through their own training programs.

The methodological proposal that we present tries to ensure that professionals who leave universities are able to join companies without the need for additional training on their part. It is therefore a question of combining the classic university training, eminently theoretical, with a practical training adapted to the needs that current companies demand.

This work has been divided into two parts, the first one that covers the analysis and organization of the contents of the training levels. In this part, courses are proposed with a greater modularization of academic contents in order to obtain graduates with a more practical and versatile training. In the second part, the evaluation aspects will be discussed. 
The first part of the training methodological proposal applied to the so-called STEM (Science, Technologies, Engineering and Matemathics) will be included in this communication, since it is the field in which we work and therefore of which we have a greater knowledge.

The proposal is aimed at changing this type of training model, for example in the area of biotechnologies as you can see in figure 2 :

\begin{tabular}{lcccccc} 
SEMESTER & S1 & S2 & S3 & S4 & S5 & S6 \\
\hline Mathematics & $\times$ & $\times$ & $\times$ & & & $\times$ \\
\hline Physics & $\times$ & $\times$ & & $\times$ & $\times$ & $\times$ \\
\hline General Chemistry & $\times$ & $\times$ & & & & \\
\hline Informatics & $\times$ & & $\times$ & $\times$ & $\times$ & \\
\hline Biology & $\times$ & & $\times$ & $\times$ & & \\
\hline Analytical Chemistry & $\times$ & $\times$ & & & $\times$ & $\times$ \\
\hline Organic Chemistry & $\times$ & $\times$ & $\times$ & & $\times$ & $\times$ \\
\hline Biochemistry & $\times$ & & $\times$ & & $\times$ & $\times$ \\
\hline Molecular Biology & & $\times$ & $\times$ & $\times$ & & $\times$ \\
\hline Communication & & $\times$ & & $\times$ & $\times$ & $\times$ \\
\hline Ethics & & & $\times$ & $\times$ & & $\times$ \\
\hline Physical Chemistry & & $\times$ & & & $\times$ & $\times$ \\
\hline Free Electives & & & $\times$ & $\times$ & $\times$ \\
\hline Bachelor's Thesis & & & & & & $\times$ \\
\hline Bachelor's Examination & & & & 180 ECTS credits
\end{tabular}

Figure 2: Scheme of a classical teaching methodology in the so-called STEM

For this other much more open model, where the student in collaboration with the tutor is selecting content to build a training itinerary, as can be seen in figure 3:

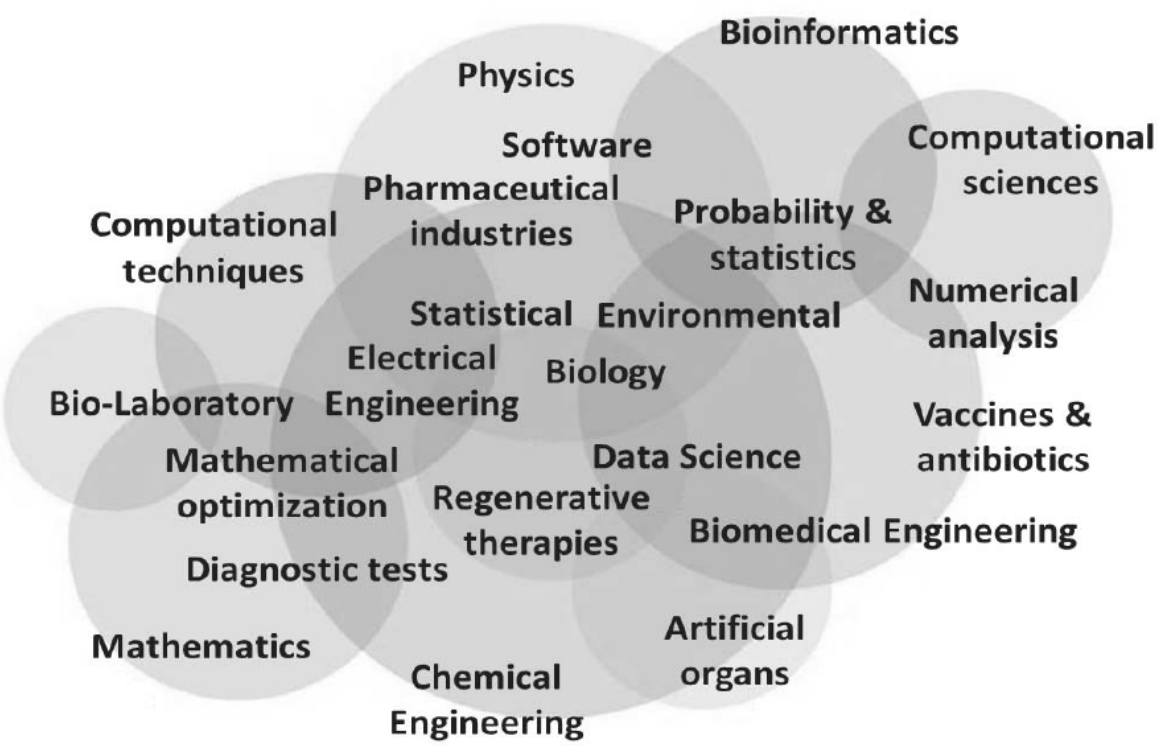

Figure 3: Scheme of the proposed methodology for the same subject

A methodology oriented to open education and Networked learning models[2] is proposed to replace traditional subjects with smaller and more operational work units, which we will call training modules, designed for teaching about collaboration and the dissemination of knowledge.

The idea is to share knowledge, learn in a collaborative environment and create work networks. 


\section{METHODOLOGY}

The basic ideas used as a reference in this work, and aimed at the study of technical training are productivity and creativity [3]. Productivity is a fundamental factor in the development of modern societies. Despite its importance, it is a concept that is not usually dealt with in education. The second idea on which we are going to base the work is creativity, which is the basis of the advancement of science and technology.

We start from the fact that the vast majority of professionals 50 years ago aspired to get a stable job for life. Nowadays, professional careers must be updated every five years or so. This leads current professionals to be in a constant learning process to update their knowledge.

On the other hand, historically the different areas of knowledge encompassed in STEM are highly diversified. Specifically, engineering activities are divided into large blocks with well-differentiated content. Civil engineering, industrial engineering, physics or mathematics... are independent studies.

The current trend is for disciplines to be increasingly related to each other but adapting the necessary knowledge to different areas. For example; in biotechnologies you have to learn to handle $\mathrm{R}$ or Python, in civil engineering you have to consider the impact of electrification on mobility and the management of autonomous systems. Issues such as smart infrastructure are an amalgamation of historically separate areas that are now juxtaposed. New tools in biology and medicine make intensive use of data and technologies.

The analysis of the two facts mentioned in the previous paragraphs leads us to the conclusion that current university education is eminently theoretical and that the division of training areas within the framework of STEM is very inefficient.

So the classical approach to university teaching is inefficient because the theoretical teachings do not allow the recycling of students easily. Therefore, the training must be oriented to the development of skills that result in the achievement of a concrete and measurable professional training.

To facilitate a more general type of learning that is easier to access for recycling and updating the knowledge of graduates in the whole of STEM, a modularization of teaching is proposed. This Modularization consists of the division of the disciplines to be studied into smaller training blocks than the current subjects, in order to achieve a more specific professional training that is adequate to the real needs of the labor market.

This approach to teaching allows, on the one hand, to train professionals more efficiently and open to the needs of a world in constant and rapid change. The unit proposed is 1 ECTS credit, equivalent to 25 or 30 hours of work. With the use of ECTS, the aim is to combine regulated and non-regulated training in the curricular description of a student.

Each module must correspond to a well-defined objective. The acquisition by the student of the skills proposed in said module, must be specified with the realization of a practical activity in which he has to demonstrate that he has acquired the minimum knowledge required to carry it out.

\section{Example:}

Contents: Programming. R. Language Management and Representation of Data. Activity: Select a collection of data and visualize the meaningful information.

The origin of the work is found in the experiences carried out in the Civil ETSI of the Polytechnic University of Madrid, some previous experiences have been developed, financed with money from the European Social Fund of the ADAPT Initiative[4]. These experiences materialized in three projects: TESME [5], BETEL [6] and TOTEL [7] that carried out different activities for the implementation of communication technologies in the improvement of the socio-economic fabric of both SMEs and the public administration.

The realization of these projects laid the foundations of the educational model that we propose in this communication, and it helped us to realize three errors that we made in the classical regulated teachings, which are summarized below:

- The regulated training level in relation to STEM areas is always far behind in relation to social reality and the job market

- Learning in computer tools is obtained mainly in the social environment and outside of educational spaces 
- People, particularly the unemployed, have far more resources and job skills than are listed on their resume

The model used to outline the learning processes is a ternary system determined by the components:

A. Creativity

B. Flexibility

C. Optimization

In the creativity component, the works are encouraged to be innovative and promote the most innovative elements.

The flexibility component fosters the ability to change, adapting to technological, scientific and economic reality.

The optimization component encourages the administrative structures to be agile, orienting the processes to simple and inexpensive organizational structures.

The problem posed by this type of ternary models is the degree of incompatibility that the three selected components have.

These elements that we consider fundamental in the formation of the 21st century are not fully developable at the same time, therefore the solutions have to choose a level of compliance in each of them.

This problem was studied in economics by Rodrik.

The modeling for the three variables, with a maximum level for the set of solutions of $100 \%$ is the diagram in figure 4 :
A. Creativity
B. Flexibility
C. Optimization

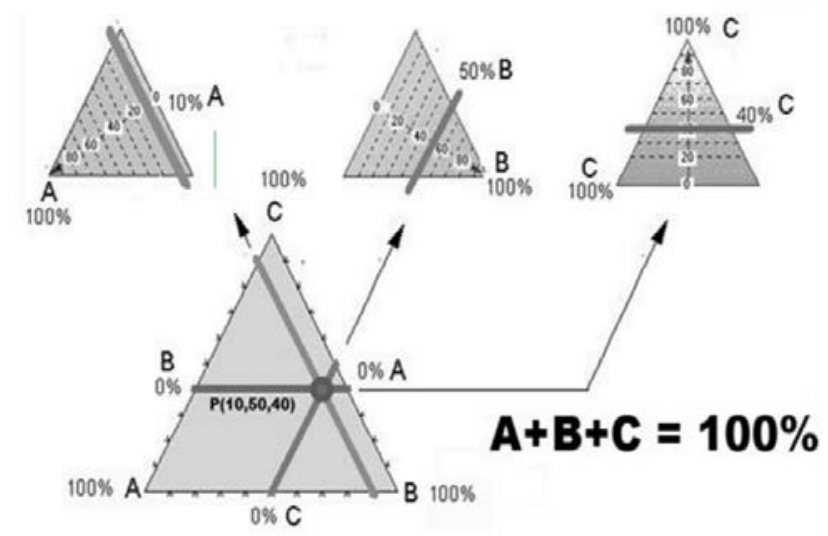

Figure 4: Scheme of a ternary learning model

The search for a solution is to select a point in the indicated scheme and these types of problems respond to the well-known Rodrik trilemma, also called the impossible trilemma.

This framework gives a very high number of solutions. This document proposes two tools to achieve the results of adaptation to changes and permanent training: the use of tools oriented to the intensive use of technological systems based fundamentally on collaboration through social networks and personal productivity tools of the OKR (Objectives and Key Results) type.

The first is the use of social networks to enhance participation in training processes. Training cannot focus on the classroom as an element of reference, but must be a medium that must be found ubiquitously in all environments in which human beings exist.

Social networks are the basis of training processes. Learning is closely related to others knowing that we have been trained in these techniques or tools.

In our professional activity we need others to be aware of our knowledge and technical skills.

Social networks are a means to carry out many activities and one of them is the training-dissemination of knowledge in an open and dynamic environment.

On the other hand, the tools for the development of activities must be analyzed. 
The conceptual models are as important as the tools for the development of the activities.

Currently a good model is the so-called OKR (Objectives and Key Results) aimed at carrying out activities focused on results. This model has become very popular after large Silicon Valley companies have been using it since the beginning of this century. This method is a variant of management methodologies based on objectives or / and results (MBO, Management by objectives, MBR, management by results) which in turn come from Peter Drucher's methodologies of the 50s.

The most important characteristics of the OKR method are:

- Objectives oriented to perform tasks

- Quantifiable results

- Simple and few tasks.

- Goals must be accepted by the interested party

- Goals must be public

- Goals need to be constantly updated

\section{RESULTS}

The problems that are observed when trying to change the regulated educational system in a profound way are on the one hand the administrative and legal aspects and on the other the inertia of the educational system, both teachers and students.

The proposal to integrate the regulated training system with lifelong learning is an urgent need. The development of tutored teaching methods, using criteria based on the OKR method or similar ones, is a necessary change to optimize teaching.

Finally, teaching has to favor collaboration and the dissemination of knowledge, the creation of work networks has to be favored.

Training has to be related to research and entrepreneurship.

Training is not a process to obtain an enabling title but a resource for the personal and social fulfillment of citizens.

The means to achieve these results are to promote public exposure of the work carried out. In this way, it is possible to commit the student and increase the quality of the works presented, since they will be accessible to other members of the community. With this procedure, dissemination and collaboration are favored, training and publishing is integrated.

The teaching units would be composed of both basic tools, such as mathematics or physics, through which students could acquire general skills, and specific tools, through which students would acquire the specific skills required for the performance of a professional activity, proposing all disciplines be developed in training units of approximately 1 ECTS per unit.

The great advantage of this type of training is the versatility and adaptability of the training of a technician in the STEM area, from scientific training to application to engineering, whether industrial or biotechnology.

The professional curriculum would be developed by a set of units that would be accessible and would give another meaning to the concept of curriculum

The student would show the activities carried out and the results of their work on their curriculum. In this way, these modules, which could be increased in number or content at any time throughout your life, lay the basis for your adaptation to changes in your professional activity.

\section{CONCLUSIONS}

Society is changing but the training processes in a large part of our academic institutions are very rigid.

The best way to adapt to a globalized and highly competitive world is to design and build the future. Training is the key tool for this process of building the future and also the key tool for increasing productivity. 
In social and political environments, the importance of productivity is not sufficiently emphasized and continuous improvement of productivity must be based on training processes.

Technical training, the so-called STEM, is the scientific, technological and industrial foundation of today's society and the pillar on which fundamental changes are supported.

STEM training is, in our opinion, one of the elements that must be urgently renewed to improve technical training, stimulate creativity and increase the productivity of processes.

Training and production must be two processes that are developed together. In such a way that on the one hand, the student obtains the results of his effort in the fastest way, and on the other hand, society takes advantage of these works, as far as possible, immediately. This will improve the productivity of technical processes.

The proposal of this work is to modularize the contents to units equivalent to an ECTS credit, between 20 and 30 hours of activity per training unit.

The fruit of this formative effort must be a unit that can be presented to others.

The works must be oriented, as far as possible, towards collaboration and the integration of the activity in working groups.

A reference is crowdlearning, in the sense that training is developed by encouraging collaborative participation.

The process of evaluating the activities that we have developed is presented in a second communication entitled "Evaluation through rubrics in STEM training within the framework of social networks".

\section{REFERENCES}

[1] Comisión Europea. Futuro de la educación en la Unión Europea en el contexto de la COVID-19 2020. https://www.europarl.europa.eu/doceo/document/B-9-2020-0338_ES.html (accessed November 12, 2020).

[2] Dori YJ, Belcher J, Bessette M, Danziger M, McKinney A, Hult E. Technology for active learning. Mater Today 2003;6:44-9. doi:10.1016/S1369-7021(03)01225-2.

[3] Colom Cañellas A, Castillejo Brull JL, Rodríguez T, Sarramona J, Touriñán López JM, Vázquez G. Creatividad, educación e innovación: emprender la tarea de ser autor y no sólo actor de sus propios proyectos 2012;10:7-29.

[4] European Commission. Evaluation of the Employment and ADAPT Community InitiativesNo Title 2000. https://cordis.europa.eu/article/id/9428-evaluation-of-the-employment-and-adaptcommunity-initiatives.

[5] Luis I. Hojas Hojas. Servicios telemáticos para PYMES. Madrid: 1998.

[6] Luis I. Hojas Hojas. Bética Telecomunicaciones (BETEL). Madrid: 2001.

[7] Luis I. Hojas Hojas. Toledo Telecomunicaciones TOTEL. Madrid: 2001. 